\title{
Wnt/Fz signaling and the cytoskeleton: potential roles in tumorigenesis
}

\author{
Shih-Lei Lai ${ }^{1,2}$, Andy J Chien ${ }^{1}$, Randall T Moon ${ }^{1}$ \\ ${ }^{1}$ Howard Hughes Medical Institute, Department of Pharmacology, Institute for Stem Cell and Regenerative Medicine, University of \\ Washington School of Medicine, Seattle, WA 98195, USA, ${ }^{2}$ Institute of Zoology, National Taiwan University, Taipei 10617
}

Wnt/ $\beta$-catenin regulates cellular functions related to tumor initiation and progression, cell proliferation, differentiation, survival, and adhesion. $\beta$-Catenin-independent $W n t$ pathways have been proposed to regulate cell polarity and migration, including metastasis. In this review, we discuss the possible roles of both $\beta$-catenin-dependent and -independent signaling pathways in tumor progression, with an emphasis on their regulation of Rho-family GTPases, cytoskeletal remodeling, and relationships with cell-cell adhesion and cilia/ciliogenesis.

Keywords: Wnt, cytoskeleton, cilia, cell adhesion, Rho

Cell Research (2009) 19:532-545. doi: 10.1038/cr.2009.41; published online 14 April 2009

\section{Introduction}

Wnts are a family of secreted glycoproteins with members that activate various intracellular pathways after binding to seven-pass transmembrane frizzled $(\mathrm{Fz})$ receptor family proteins or to a complex comprised of $\mathrm{Fz}$ and LDL receptor-related proteins 5/6 (LRP5/6). The best studied Wnt pathway is the Wnt/ $\beta$-catenin pathway, also known as the "canonical" Wnt pathway. In the absence of Wnt ligands, $\beta$-catenin is recruited into a destruction complex comprised of adenomatous polyposis coli (APC) and Axin, which induce the phosphorylation of $\beta$-catenin by casein kinase 1 (CK1) and glycogen synthase kinase 3 (GSK3). This phosphorylation leads to the ubiquitylation and proteasomal degradation of $\beta$-catenin (Figure 1A). Upon binding of Wnts to Fz and LRP5/6 receptors, a signal is transduced to activate the cytoplasmic phosphoprotein Dishevelled (DVL). Activated DVL then recruits the destruction complex to the plasma membrane, inhibiting GSK3 and thus preventing phosphorylation of $\beta$-catenin. In addition, phosphorylation of LRP5/6 at intracellular PPPSP motifs by CK1 and GSK3 also stimulates Axin recruitment to the plasma membrane $[1,2]$. Consequently, $\beta$-catenin escapes proteasomal degradation, accumulates in the cytoplasm and subsequently

Correspondence: Randall T Moon

E-mail:rtmoon@u.washington.edu translocates to the nucleus, where it activates target gene transcription in cooperation with T-cell factor (TCF) and lymphoid enhancer-binding protein transcription factors (LEFs; Figure 1B, for reviews, see [3-6]).

The term non-canonical Wnt pathway has been used in the literature to refer to Wnt-activated signal transduction independent of $\beta$-catenin stabilization. At least two non-canonical pathways have been summarized in previous reviews [7-9]. However, it is still unclear whether non-canonical Wnt pathways represent truly distinct pathways or whether they are all parts of a large incompletely characterized signaling network.

One candidate $\beta$-catenin-independent Wnt pathway is the planar cell polarity (PCP) pathway, which was first elucidated in Drosophila (Figure 2A). Genetic studies revealed the asymmetric distribution of core PCP gene products that include Frizzled $(F z), D V L$, Prickle $(P k)$, Flamingo (Fmi/CELSR) and Strabismus (Stbm/ $V A N G L 2)$. PCP signaling is pivotal for establishing cell polarity in the orientation of wing hairs, the organization of multifaceted eye structures, the orientation of hair cells in the inner ear, and the orientation of bristles and other asymmetric polar structures. Activation of the PCP pathway leads to subcellular-localized activation of Rho-family GTPases and JNK, which are involved in processes such as embryonic convergent extension (CE) in Xenopus [10].

Involvement of the established $\mathrm{Wnt} / \beta$-catenin pathway members Fz and DVL, along with phenotypic simi- 

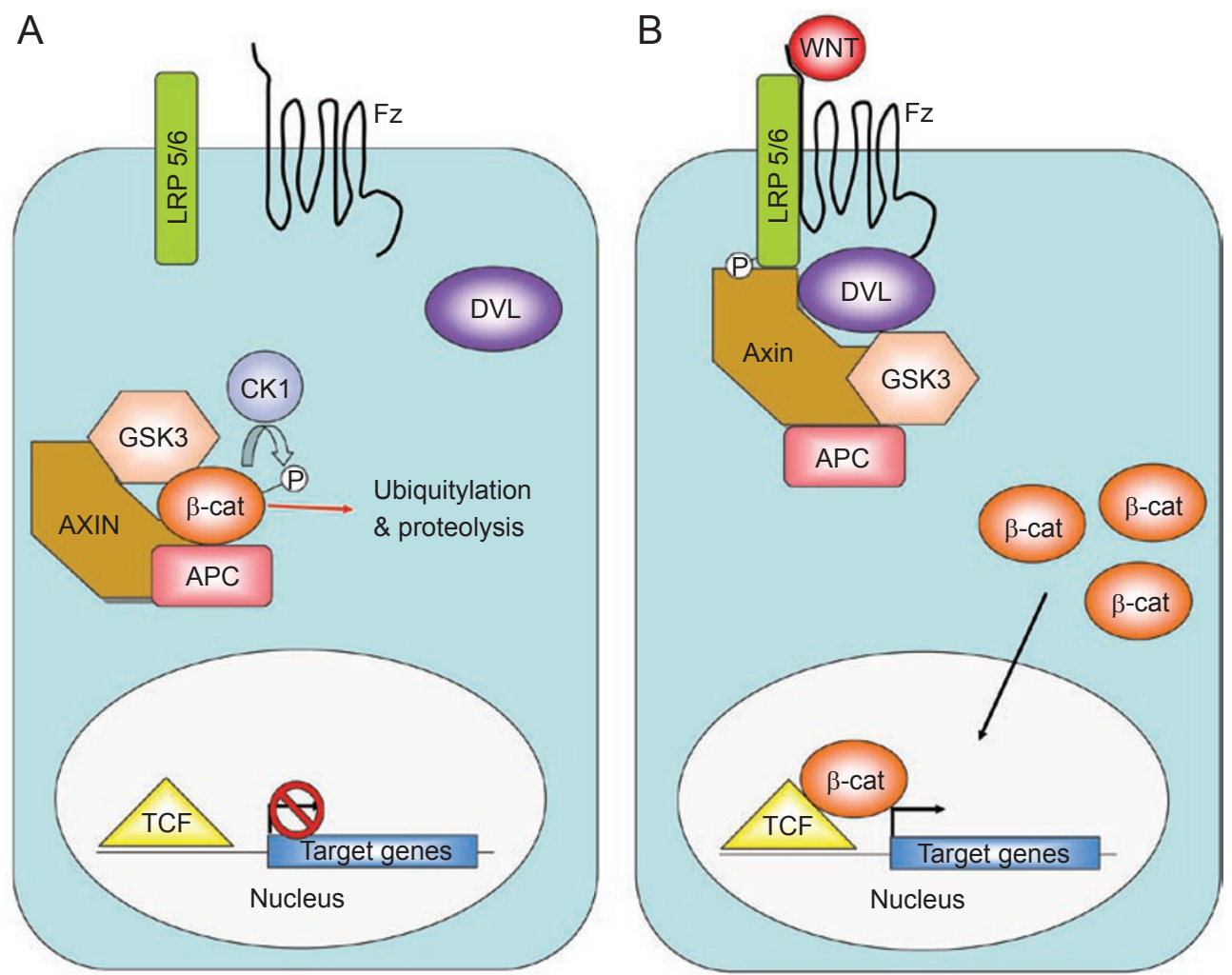

Figure 1 Overview of the canonical Wnt- $\beta$-catenin pathway. (A) In the absence of Wnt, $\beta$-catenin ( $\beta$-cat) is recruited into the destruction complex comprised of adenomatous polyposis coli (APC) and Axin, and phosphorylated by casein kinase 1 (CK1) and glycogen synthase kinase 3 (GSK3). This finally leads to the ubiquitylation and proteolysis of $\beta$-catenin. (B) Upon binding of Wnt to frizzled (Fz) and LDL receptor-related proteins 5/6 (LRP5/6), active Dishevelled (DVL) recruits the destruction complex to the plasma membrane and prevents $\beta$-catenin degradation. Accumulated cytosolic $\beta$-catenin subsequently translocates into the nucleus and activates target genes in cooperation with T-cell factor (TCF) and lymphoid enhancer-binding protein transcription factor (LEF).

larities between PCP mutants and gain-of-function or loss-of-function phenotypes for certain Wnt isoforms, has led to the hypothesis that PCP signaling is a $\beta$-cateninindependent Wnt pathway, and, consequently, the term $\mathrm{Wnt} / \mathrm{PCP}$ is often utilized. However, no specific Wnt isoform has definitively linked Fz-dependent activation by a Wnt to PCP signaling in Drosophila. In vertebrates, Wnt5, Wnt11 and homologs of PCP genes are involved in regulating $\mathrm{CE}$ movements in the gastrulation phase of embryonic development [8]. Stbm/VANGL2 mutant trilobite fish have a severe CE defect that is mimicked by both overexpression and morpholino knockdown of Stbm/VANGL2 in both zebrafish and Xenopus [11-13]. In addition, mutation of Stbm/VANGL2 in loop-tail mice also results in defective neural tube closure, likely due to CE failure [14]. Furthermore, mutation of CELSR in mice and morpholino gene knockdown of zebrafish and Xenopus $P k$ showed similar effects on CE movement [15-18]. The CE defects seen upon gain-of-function or loss-of-function of genes implicated in Wnt/PCP signaling have led to the hypothesis that this pathway may regulate cellular adhesion and/or cellular motility. In addition to $\mathrm{CE}$, another distinctive epithelial PCP seen in vertebrates is the uniform orientation of stereocilia on sensory hair cells in the mammalian cochlea. Wnt5a is required for proper cellular distribution of Ltap/Vang12 and genetically interacts with Ltap/Vangl2 for uniform orientation of stereocilia, cochlear extension and neural tube closure [19]. Even though there is evidence suggesting that Wnt signaling is one of the signals to break the symmetry of these PCP components, the exact contribution of Wnt is still unclear.

Another proposed $\beta$-catenin-independent pathway, the Wnt-calcium (Wnt $/ \mathrm{Ca}^{2+}$ ) pathway, is less understood, and is defined by cell physiology, biochemistry and genetics (Figure 2B, for reviews, see $[8,20,21]$ ). The involvement of certain Wnt isoforms in activating both the Wnt/ $\mathrm{Ca}^{2+}$ and $\mathrm{Wnt} / \mathrm{PCP}$ pathways in vertebrates, as well as the 

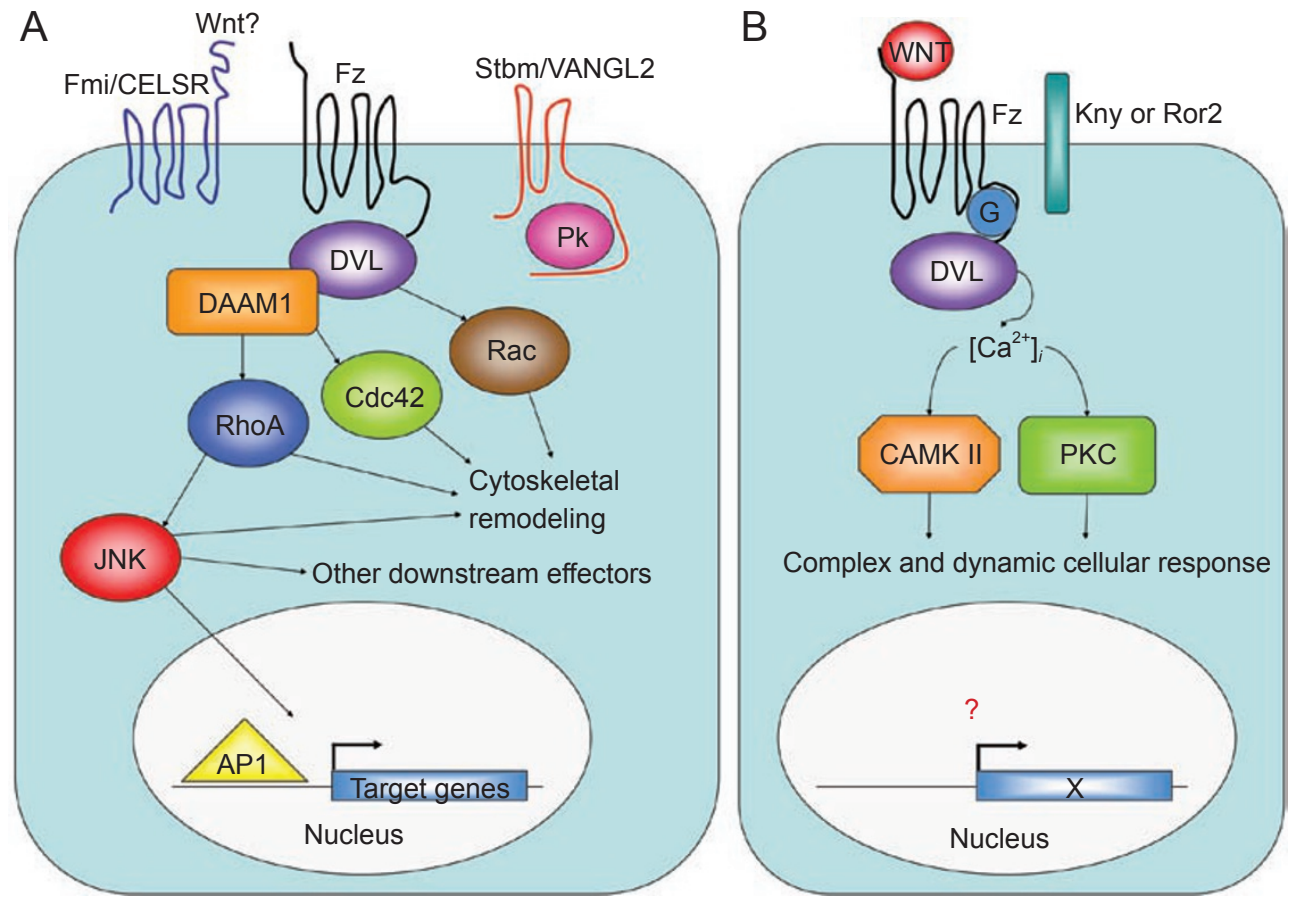

Figure 2 Overview of $\beta$-catenin-independent Wnt pathways. (A) The Wnt/PCP pathway is characterized by asymmetric distribution of Frizzled (Fz), Flamingo (Fmi/CELSR), Prickle (Pk) and Strabismus (Stbm/VANGL2), resulting in cell polarity and the activation of Rho GTPases and JNK through DVL and Dishevelled-associated activator of morphogenesis 1 (DAAM1). (B) Activation of the Wnt-calcium pathway by interaction of Wnts with Fz and co-receptor Kny or Ror2 increases intracellular calcium level and subsequently activates calcium/calmodulin-dependent protein kinase II (CAMKII) and protein kinase C (PKC).

involvement of shared intracellular components between the two pathways, offers some evidence that these two pathways may be part of the same signaling network. Certain Wnt ligands, particularly Wnt5a and Wnt11, trigger the release of intracellular calcium and utilize both G-proteins and DVL during this process in certain cellular contexts $[22,23]$. The signaling specificity between $\mathrm{Wnt} / \beta$-catenin and $\mathrm{Wnt} / \mathrm{Ca}^{2+}$ pathways relies partially on participation of co-receptors, such as LRP5/6 in the Wnt $/ \beta$ catenin pathway and Knypek and Ror2 in the Wnt/Ca ${ }^{2+}$ pathway [24, 25]. Increased levels of intracellular calcium subsequently modulate calcium-sensitive proteins such as calcium/calmodulin-dependent protein kinase II (CaMKII) and protein kinase C (PKC) $[23,26]$.

Like the Wnt/PCP pathway, the $\mathrm{Wnt} / \mathrm{Ca}^{2+}$ pathway has also been postulated to play a crucial role in cell adhesion and/or cell movements during gastrulation [27]. Intracellular calcium waves have been observed at the margin of gastrulating zebrafish embryos [28] and dorsal explants of gastrulating Xenopus embryos [29], and pharmacologically inhibiting this calcium wave results in CE defects without affecting cell fate [29]. By the same logic, zygotically mutant zebrafish embryos for Wnt5 (known as the pipetail mutant) show a reduction in calcium transient frequency [30], and CE defects [31]. In addition, expression of CaMKII partially rescues CE defects of Wnt5/pipetail mutants, suggesting the involvement of CaMKII in this process [30]. In the context of tumor progression, overexpression of Wnt5a in melanoma cells induces actin reorganization and increased cell invasion, through the activation of PKC [32]. This PKC activation by Wnt5a is most likely through the calcium release since Wnt5a-induced calcium release has also been shown in both human mammary epithelial cells [33] and mouse F9 teratocarcinoma cells [34].

In the context of cancer biology, the Wnt/ $\beta$-catenin pathway is implicated in the initiation and progression of various types of tumors, most likely through the regulation of $\beta$-catenin-responsive genes affecting cell fate, growth and apoptosis [3]. The majority of research on Wnt signaling and oncogenesis has focused on the role of mutations or aberrant expression of Wnt signaling components in promoting dysregulation of the $\mathrm{Wnt} / \beta$-catenin pathway and target gene expression. By contrast, there are only limited studies on the cytoskeletal-remodeling roles of Wnt in tumor progression. In this review, we will summarize the research on Wnt-mediated cytoskeletal remodeling and its potential role in both embryonic de- 
velopment and tumorigenesis.

\section{Wnt signaling and cytoskeleton}

\section{Dishevelled}

DVL is a central molecule in coordinating both $\beta$ catenin-dependent and $\beta$-catenin-independent Wnt signaling and plays a role in various physiological and morphogenetic processes involving cytoskeletal interactions. DVL-1 co-localizes with axonal microtubules and stabilizes them through inhibition of GSK3 $\beta$ [35]. This cytoskeletal association is induced by Axin and correlates with a decreased phosphorylation of MAP-1B by GSK3 $\beta$ [36]. JNK is also involved in this Wnt/DVLmediated microtubule stabilization pathway independent of Rho GTPases [37]. JNK1-deficient mice show progressive degeneration of long nerve fibers and loss of microtubule integrity in dendrites, which correlates with hypophosphorylation of MAP-2 and disruption of tubulin polymerization [38]. For a summary of the domain structures of DVL and their interactions, see Figure 3. DVL controls processes including the establishment of cell polarity, neuronal dendrite formation/outgrowth, cell-cell adhesion and gastrulation morphogenesis through $\beta$-catenin-independent Wnt signaling. Disruption of cell-cell contacts activates the Wnt/DVL pathway, which cooperates with $\mathrm{Cdc} 42 / \mathrm{Par} 6 / \mathrm{aPKC}$ to promote polarization of microtubule cytoskeleton [39]. In hippocampal neurons, Wnt5a induces axon differentiation through the activation of DVL and aPKC in a Par3/Par6/ aPKC complex [40], while DVL activates Rac and JNK to promote dendrite arborization under Wnt-7b signaling [41]. Furthermore, DVL also promotes neurite outgrowth in neuronal differentiating neuroblastoma $2 \mathrm{~A}$ cells via a DIX-domain-dependent pathway independent of $\beta$ catenin and GSK3 [42]. DVL interacts with actin stress fibers and vesicular membranes through its DIX domain. This might be a divergence point in Wnt signaling, which may provide a mechanism for divergent activation of $\beta$-catenin-dependent and -independent Wnt signaling by partitioning DVL into cytoskeletal and vesicular $(\beta-$ catenin signaling) pools [43].

\section{Adenomatous polyposis coli}

A growing body of literature regarding Wnt-related cytoskeletal interactions in cancer and other contexts concentrates on the APC gene, which is mutated in $>80 \%$ of sporadic colorectal tumors [44]. Like DVL, APC may also be regulated in various different intracellular pools. Since APC was identified as a member of the $\beta$-catenin destruction complex, research on the effect of APC mutation in colorectal tumors has primarily focused on the

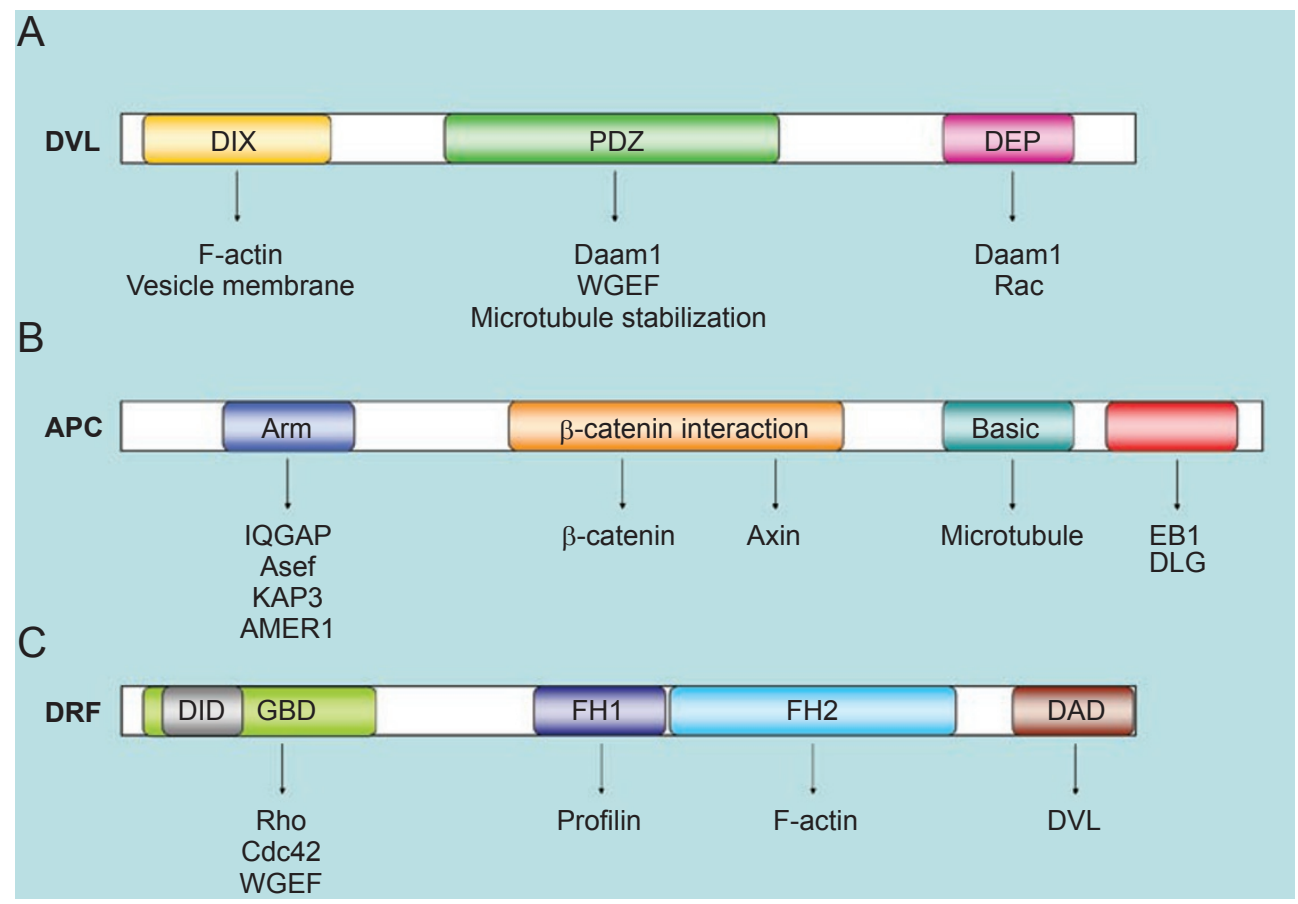

Figure 3 Protein structures of (A) DVL, (B) APC and (C) Diaphanous-related formins (DRF). Domain structures of these three proteins and their corresponding interacting partners are indicated. 
accumulation of nuclear $\beta$-catenin and the consequent changes in $\beta$-catenin-mediated gene transcription [4548]. Additionally, APC also interacts with several proteins linked to the cytoskeleton, including Axin, APCstimulated guanine nucleotide exchange factor (Asef), IQ motif-containing GTPase activating protein 1 (IQGAP1), kinesin superfamily-associated protein 3 (KAP3), endbinding protein 1 (EB1), microtubules and Drosophila discs large (DLG) through different domains or repeats (Figure 3). Most of the APC mutations found in colon cancer are truncations that retain the $\mathrm{N}$-terminal armadillo repeat domain, with loss of the $\mathrm{C}$-terminal sites that bind Axin and $\beta$-catenin, resulting in a mutant protein that fails to induce $\beta$-catenin degradation. The overall result is activation of the $\mathrm{Wnt} / \beta$-catenin pathway, similar to what is seen with activating mutations of $\beta$-catenin that can be found in small colorectal adenomas [49].

Several observations have highlighted the potential importance of the interaction between APC and microtubules, as well as the potential impact of these interactions on cell migration in contexts relevant to cancer biology. APC has been shown to move along microtubules and concentrate at their growing ends in epithelial cells [50]. APC interacts with microtubules via direct binding to the basic region in its C-terminus [51], by indirect association via $\mathrm{EB} 1[52,53]$ and by interacting with kinesin superfamily proteins [54]. The interaction between APC and EB1 has been shown only in a subset of microtubule growing ends, and it has been postulated that this interaction may play an important role in the regulation of cell migration by APC [55]. APC and EB1 stabilize microtubules downstream of Rho and the forminhomology protein $\mathrm{mDia}$, forming a complex at stable microtubule ends. Loss-of-function studies, including RNAi knockdown of EB1 and expression of dominantnegative EB1 mutant, show that this interaction is crucial for microtubule stabilization and fibroblast cell migration in wounding assays [56]. Furthermore, phosphorylation of APC by GSK3 prevents APC-microtubule association [57] and also prevents the accumulation of APC at cell protrusions [58]. Subcellular localization of APC is also regulated by APC membrane recruitment 1 (AMER1), a membrane-associated protein that interacts with the armadillo repeat of APC. Overexpression of AMER1 increases APC level and recruits APC from microtubule ends to the plasma membrane of epithelial cells. On the contrary, knockdown of AMERl by siRNA reduces APC level and promotes its association with microtubule ends in cellular protrusions [59]. APC also interacts with kinesin superfamily (KIF) proteins KIF-3a and KIF-3b through the association with KAP3, and this interaction is required for its accumulation in clusters near the distal ends of microtubules at the edges of migrating epithelial cells $[54,60]$. APC mutants found in cancer cells were unable to accumulate in clusters, and thus may contribute to dysregulation of cell migration [54].

Whether or not regulation of microtubule stability by APC and EB1 is controlled by Wnts remains unclear. As for the roles of Wnt signaling in controlling microtubule cytoskeleton in model animals, the plane of cell division in Caenorhabditis elegans and Drosophila and axon remodeling are best studied (for review, see [61]). Wnt, Frizzled, dsh2 and gsk3 regulate the asymmetric cell division in EMS blastomere of $C$. elegans embryos, possibly through local enrichment of dynactin complex at the P2-EMS border and alignment of their spindle along the defined axis $[62,63]$. APC is also required for proper symmetric cell division in the Drosophila epithelium. Knockdown of APC by siRNA leads to asymmetric cell division in epithelial cells [64]. In axon terminal remodeling, Wnt3a decreases endogenous APC from the microtubule plus end and induces the loss of microtubule growth directionality, resulting in microtubule looping. Subsequently, the speed of growth cone advance decreases and growth cone size increases [65]. These results support a direct role for canonical Wnt signaling components, such as Wnt3a, Dvl, GSK3 $\beta$ and APC, in microtubule regulation.

As mentioned previously, APC interacts with the IQGAP1 via its armadillo repeat domain, leading to accumulation of APC/IQGAP complexes at the leading edge of the lamellipodia [66]. IQGAP1 has been implicated as a scaffolding protein that modulates crosstalk among diverse pathways [67]. IQGAP1 interacts with active $\mathrm{Rac}$ and $\mathrm{Cdc} 42$, and directly binds to and crosslinks actin filaments [68]. IQGAP1 also localizes microtubules through interaction with CLIP-170 as a Rac1 and Cdc42 effector in cell polarization and migration [69]. Depletion of APC or IQGAP1 inhibits the accumulation of Rac1 and $\mathrm{Cdc} 42$ at the leading edge of migrating cells, disrupts localized actin meshwork formation and inhibits overall cell migration in a wounding assay, suggesting that these four proteins interact as a complex in migrating cells [66]. With regard to tumorigenesis, IQGAP1 can bind to truncated mutant APC in colon cancer cells; therefore, interactions between APC and the cytoskeleton could potentially be involved in the dysregulation of cell polarity/motility changes. A role for Wnt ligands, Fz or Dvl upstream of this IQGAP-Cdc42 pathway remains to be elucidated.

Truncated APC in colon cancer could also cause decreased cell adhesion and aberrant migratory properties through interaction with the Asef, a Rac-specific GEF that stimulates cell flattening, membrane ruffling and 
lamellipodia formation in MDCK cells. Its GEF activity highly relies on the interaction with the $\mathrm{N}$-terminal armadillo repeat domain of APC [70]. In colorectal carcinoma cells, both Asef and mutant APC are required for cell migration, which potentially involves dysregulation of cadherin-mediated cell adhesion $[71,72]$.

The effects of APC loss-of-function on cell motility and cell migration are still unclear in zebrafish, since no phenotypes regarding these aspects have been reported so far. However, these fish still exhibit some phenotypes that may lend insight into the role of APC in cancer biology. APC-mutated zebrafish reveal dual roles of APC in controlling both retinoic acid biosynthesis and $\beta$-catenin stabilization [73], and these mutant fish show developmental abnormalities of both the lens and retina. In addition to $\beta$-catenin stabilization, APC mutation also inhibits retinoic acid biosynthesis through a $\beta$-cateninindependent mechanism, and impaired retinoic acid biosynthesis leads to increased cyclooxygenase-2 (COX-2) expression through up-regulation of the transcription factor C/EBP- $\beta$ [74]. More studies on zebrafish APC mutants, as well as on the hypomorphic APC mouse model, will likely clarify how the diverse functions of this protein relate to its pivotal role in colon carcinogenesis, and potentially in other cancer settings as well.

\section{Diaphanous-related formin-homology proteins}

Despite many studies demonstrating that homologs of Drosophila core-PCP components are involved in the regulation of vertebrate $\mathrm{CE}$ movements, the molecular mechanisms underlying this process remain largely unclear; studies have focused largely on the link between Wnt pathway components and the cytoskeleton. Among $\beta$-catenin-independent pathways, the implicated involvement of Rho-family GTPases and their effectors provides the most obvious connection to cytoskeleton remodeling. $\beta$-Catenin-independent Wnt signaling can activate Rho family GTPases through at least two mechanisms: (1) direct activation of Rac1 by DVL; and (2) activation of RhoA via DVL-associated activator of morphogenesis-1 (Daam1), possibly through the weak-similarity guaninenucleotide exchange factor (WGEF) [75]. Daam1 belongs to a group of proteins known as formins, a large family that regulate actin-filament assembly in response to various signals [76-78]. Formins are defined by the highly conserved formin-homology domains 1 and 2 (FH1 and FH2). The FH1 domain contains poly-proline stretches and binds to proteins with $\mathrm{SH} 3$ domains, such as the actin-binding protein profilin, while the $\mathrm{FH} 2$ domain binds actin directly and can promote filamentous actin nucleation. In addition, they have been shown to protect the barbed end of actin filaments [79, 80]. Form- ins are crucial for a variety of cellular functions, including cell protrusion, polarized-cell growth, vesicular transport, cell polarity establishment and cell migration [81, 82].

A recent phylogenic study on formin-homology proteins showed that metazoan $\mathrm{FH} 2$ domains segregate into seven subfamilies and three of them have high similarity on domain structures outside the FH2 domain, including Diaphanous (Dia), Daam and formin-related gene in leukocytes (FRL), which together form a subclass of Diaphanous-related formins [83]. These domains include a GTPase-binding domain (GBD), a Diaphanous-inhibitory domain (DID) and a coiled-coil region, followed by FH1, FH2 and the C-terminal Diaphanous autoregulatory domain (DAD) [77]. In the resting state, these Diaphanous-related formins exert autoinhibition through the intra-molecular interaction of N-terminal DID and Cterminal DAD. This autoinhibition is relieved upon binding to active Rho-family GTPases (GTP-bound) through the GBD, which triggers a structural change and exposes the $\mathrm{FH} 2$ domain, thus triggering actin polymerization [82, 84, 85] (Figure 3).

Daam1 was shown to be involved in Wnt/Fz signaling during Xenopus gastrulation through direct binding to the DEP and PDZ domains of DVL and to Rho GTPase through its GBD [86]. Unlike other Diaphanousrelated formins that are activated by Rho-family GTPases, Daam 1 is activated upon Wnt/Fz signaling by DVL through the interaction of DVL with its DAD domain and the release of its auto-inhibitory conformation [87]. Active Daam1 subsequently activates Rho through WGEF, leading to cytoskeletal remodeling via downstream effectors, possibly Rho kinase (Rok) and Diaphanous (via interaction with profilin and actin) [88-91]. Consistently, Daam1 collaborates with Rho, Cdc42, CIP4 and Src in the formation of branched protrusions and in reorganizing the actin cytoskeleton [92].

Daam1 has already been implicated in cancer through its regulation of the endocytosis of ephrin B (EphB) receptors [93]. Ephrins and Eph receptors signal to induce cytoskeletal changes necessary for the invasive capacity of melanoma cells, which is dependent on proper localization and activity of RhoA [94]. In addition, $\beta$-catenin and TCF inversely control the expression of the EphB2/ EphB3 receptors and their ligand ephrin-B1 in colorectal cancer [95]. Reduced expression of EphB2 also parallels invasion and metastasis in colorectal tumors [96]. The ability of Wnts to activate Daam 1 could also consequently regulate membrane levels of EphB by providing spatial cues for Rho activation and the triggering of RhoA and/or Daam1-mediated endocytosis of EphB or other membrane proteins. The loss of EphB enhances tumor 
formation in APC-deficient mice, further highlighting the link between Wnt signaling and proteins, such as EphB, that are involved in cytoskeletal remodeling [97].

Dia1 is also involved in Wnt-regulated CE movements in vertebrates [98]. Overexpression of human Dial can rescue gastrulation defects caused by both Wnt11 and RhoA knockdown in zebrafish, suggesting that Dia1 acts as a major effector downstream of both Wnt and RhoA $[88,98,99]$. The closely related zebrafish Dia2 is also activated by RhoA and cooperates with profilin I to control actin assembly and cell protrusion during zebrafish gastrulation (Lai et al., unpublished). In the context of cancer, there are some initial reports on the potential link between Wnt and Dia1. In melanoma cells, the Wntregulated target micropthalmia transcription factor (Mitf) epigenetically controls melanoma proliferation and invasiveness through Dia1. Low Mitf levels lead to downregulation of Dia1, with resultant reorganization of the actin cytoskeleton and increased ROCK-dependent invasiveness. By contrast, increased Mitf expression leads to decreased invasiveness [100].

In summary, subcellular localization and regulation of Diaphanous-related formins by Wnt signaling seem to be important for both their effector roles and their regulation of cellular processes, including the activation of Rho GTPases and direct effects on cytoskeletal remodeling. Understanding the mechanisms by which Diaphanousrelated formins are regulated will provide more insights into how these proteins may participate in motility and metastasis in cancer cells. In addition, they may provide important clues as to how $\beta$-catenin-independent $\mathrm{Wnt}$ signaling may affect tumor progression through the regulation of cytoskeletal processes.

\section{Rho-family GTPases}

Wnt signaling activates several members of Rho family GTPases to affect cellular function. Rho family GTPases are well-known regulators for cell growth, morphology change, polarity establishment, cell cycle regulation, as well as invasion and migration, which are fundamental steps in tumorigenesis. Although $\mathrm{RhoH}$ is the only member of Rho family known to be altered genetically in human cancer [101], changes in other Rho activity regulators have been reported in tumor progression. Leukemia-associated Rho guanine nucleotide exchange factor (LARG), a Rho-specific GEF, has been isolated as a fusion partner of the mixed-lineage leukemia (MLL) gene in a patient with acute myeloid leukemia (AML) [102, 103]. Another GEF, Tiam-1, has been found mutated in renal carcinomas, and this mutation results in constitutively active Tiam-1 and sustained Rac1 activation. Links between Rho GTPases and metastasis have also been shown. By studying genes that correlate to metastatic phenotype, RhoC was found to enhance metastasis when overexpressed, whereas a dominantnegative RhoC inhibited metastasis [104]. In addition, overexpression of other members of the Rho family or some upstream or downstream components of Rho signaling has been detected in many human tumors [105]. For a detailed review on how Rho GTPases are involved in tumorigenesis, see [106].

Rho GTPases and their regulators likely exert their roles in tumor progression through regulation of both cytoskeletal remodeling and gene expression. Activation of Cdc42 by Wnt5a and Src-family kinase Yes in human mammary epithelial cells can counteract $\mathrm{Wnt} 5 \mathrm{a} / \mathrm{Ca}^{2+}$-induced nuclear factor of activated T-cells (NFAT) activity, a transcription factor implicated in invasive breast cancer and metastasis [107, 108], through serine phosphorylation by casein kinase I [33]. We have described how $\beta$-catenin-independent Wnt signaling activates RhoA and Rac1 in regulation of actin cytoskeleton previously, and we will discuss another parallel pathway involving RhoB and Rab4, which regulate distribution of adhesion molecules, in the following section. However, the significance of Wnt regulation of Rho family GTPases in tumor progression needs to be elucidated by more intensive studies. References linking selected Wnt components and cytoskeleton-related proteins are summarized in Table 1.

Table 1 Summarized references showing the interaction of DVL, APC and Daam1 with their cytoskeletal-related interacting proteins

\begin{tabular}{llc}
\hline $\begin{array}{c}\text { Pathway } \\
\text { components }\end{array}$ & Cytoskeletal-related & References \\
\hline Dishevelled & Actin stress fiber & \\
& Daam1 & {$[43]$} \\
& Rac & {$[86]$} \\
& WGEF & {$[89]$} \\
APC & IQGAP & {$[75]$} \\
& Asef & {$[66]$} \\
Microtubule & {$[70]$} \\
& mDia & {$[51]$} \\
& EB1 & {$[56]$} \\
KAP3 & {$[56]$} \\
AMER1 & {$[54]$} \\
Actin & {$[59]$} \\
& Rho & {$[91]$} \\
& Cdc42 & {$[86]$} \\
& Profilin & {$[92]$} \\
& WGEF & {$[90]$} \\
\hline
\end{tabular}




\section{Wnt signaling and cell adhesion}

\section{Wnt signaling and adhesion complex}

The loss of cell adhesion has been implicated in the progression of cancer, particularly with regard to models of epithelial-to-mesenchymal transitions (EMT) and loss of the extracellular adhesion protein E-cadherin. Adherent junctions are composed of E-cadherin and catenin family proteins, including $\alpha$-catenin, $\beta$-catenin and $\mathrm{p} 120$ catenin. As mentioned above, a strong link has been revealed between mutations in canonical Wnt pathway components (such as APC truncations), which in turn affect cytosolic $\beta$-catenin stability, and tumor progression $[45,48,109-111]$. Thus, the balance of $\beta$-catenin in adherent junctions and in the activation of target gene transcription is likely critical to several aspects of tumor cell biology.

Serine-threonine phosphorylation at the amino-terminus of $\beta$-catenin by CK 1 and GSK $3 \beta$ induces the binding of $\beta$-catenin to $\beta$-TrCP ( $\beta$-transducin repeat-containing protein), an E3-ligase that promotes the degradation of "cytosolic" $\beta$-catenin [112-114]. The mechanism that regulates the balance between cytosolic $\beta$-catenin and $\beta$-catenin in adherent junctions (so-called "junctional $\beta$ catenin") also relies on site-specific phosphorylation [115] (Figure 4A). Phosphorylation of tyrosines 142 and 654 in the first and last armadillo repeats of $\beta$-catenin leads to the disassembly of the E-cadherin $/ \beta$-catenin $/ \alpha$-catenin complex at the plasma membrane and to increased $\beta$ - catenin-dependent transcription [116-120]. This regulatory mechanism modulates the ability of $\beta$-catenin to bind different interacting partners, especially E-cadherin, which is a critical player in EMT, and the progression of malignancy in tumors. For example, tyrosine 654 of $\beta$-catenin is essential for E-cadherin binding, and phosphorylation of this residue prevents this interaction [116, $120,121]$. On the other hand, tyrosine 142 of $\beta$-catenin is crucial for $\beta$-catenin interaction [117-119, 122]. This residue interacts intra-molecularly with other residues to form a stabilized armadillo repeat for $\alpha$-catenin interaction, and mutation or phosphorylation of this residue abolishes $\beta$-catenin $/ \alpha$-catenin interaction $[117,118,122]$. Overexpression of tyrosine kinases and mutations in tyrosine phosphatase genes that might facilitate the phosphorylation of $\beta$-catenin have been identified in tumors $[123,124]$. Particularly, the non-receptor tyrosine kinases Met and c-Src are overexpressed in a number of human malignancies [123, 125-127].

Although tyrosine phosphorylation of $\beta$-catenin disrupts its interactions with E-cadherin and $\alpha$-catenin, which in turn affects the assembly of adhesion complex, it does not affect the interaction of $\beta$-catenin with TCF/ LEF proteins. TCF/LEF binds to $\beta$-catenin at a region overlapping with E-cadherin binding in the central armadillo domain, but the last armadillo repeat, which contains tyrosine 654, is not required for their binding [120, 128-131]. Loss of E-cadherin-mediated cell adhesion also correlates with increased $\beta$-catenin-dependent tran-

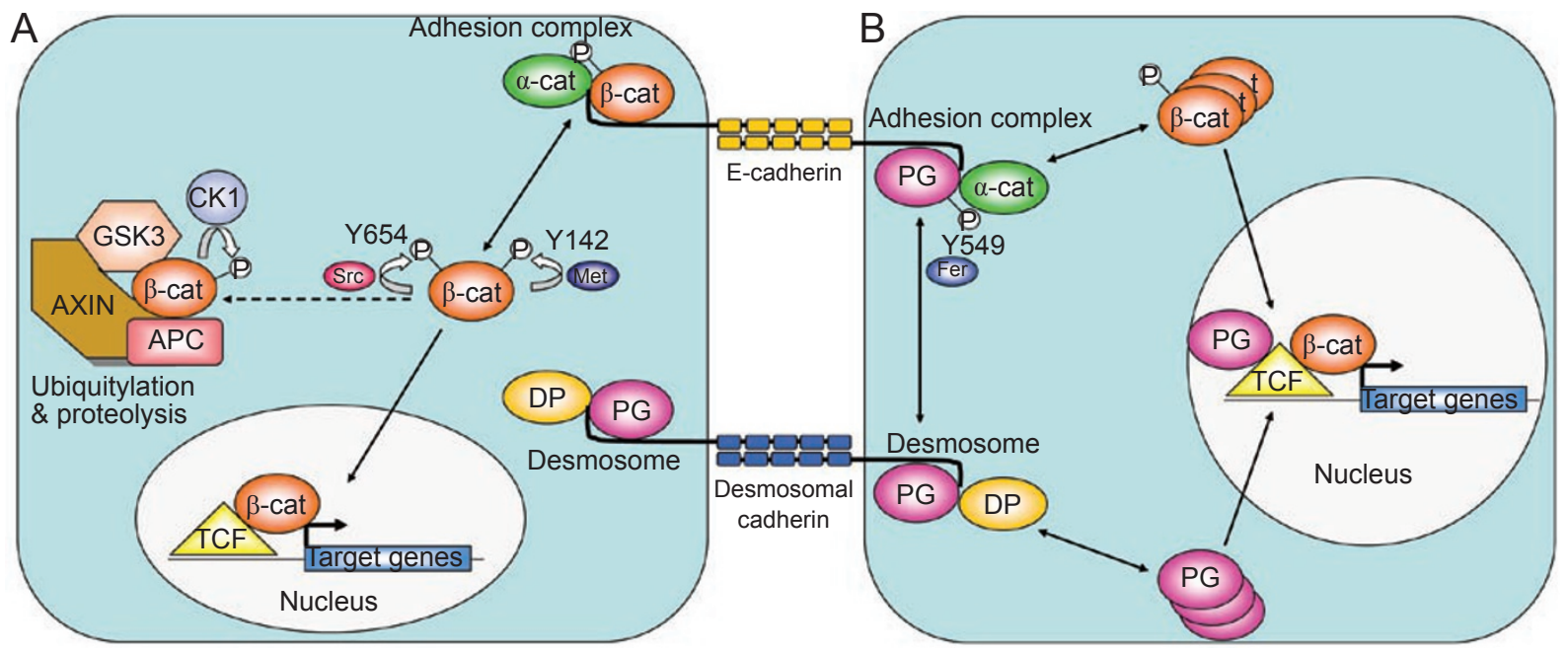

Figure 4 Wnt signaling and cell adhesion. (A) Adherent junctions are comprised of E-cadherin, $\beta$-catenin and $\alpha$-catenin. (B) $\beta$-catenin and plakoglobin (PG) are interchangeable between adherent junctions and desmosomes, which are mainly comprised of desmosomal cadherin, PG and desmoplakin (DP). Phosphorylation of PG increases the affinity of PG to $\alpha$-catenin, triggering the substitution of $P G$ for $\beta$-catenin in adherent junctions and the subsequent activation/repression of transcription of target genes in cooperation with TCF/LEF. 
scription $[128,132,133]$. This may partly explain how dysregulation of tyrosine kinases/phosphatases such as Met and c-Src contributes to tumor progression in certain contexts.

Consistent with this concept, proteoglycan Glypican-3 (GPC3) could serve as a metastasis suppressor in mammary tumor LM3 cells partly through increasing E-cadherin expression and E-cadherin/ $\beta$-catenin association [134]. It was suggested that suppression of canonical Wnt pathway by re-expressing GPC3 in LM3 cells increased E-cadherin transcription in LM3-GPC3 cells and the enhanced level of E-cadherin could sequester more $\beta$-catenin to the membrane, inhibit their signaling function and generate a negative feedback loop. In turn, the increased number of E-cadherin/ $\beta$-catenin complexes leads to higher homotypic adhesion and less motile phenotype.

In another context of cancer, the melanoma cell adhesion molecule (MCAM, also known as MUC18 or CD146) in dispersed melanoma cells has recently been shown to be redistributed upon Wnt5a stimulation [135]. MCAM is an immunoglobulin G-family cell adhesion receptor, which has been implicated in melanoma tumorigenesis and metastasis [136]. Wnt5a induced redistribution of MCAM into a polarized structure called Wnt5amediated receptor-actin-myosin polarity (W-RAMP) in the presence of gradient cue CXCL12. This process requires non-canonical Wnt signaling components Dvl2 and $\mathrm{PKC}$, and involves membrane internalization and endosome trafficking regulated by RhoB and Rab4, and remodeling of cytoskeletal protein actin and myosin IIB. The W-RAMP structure subsequently triggers membrane contractility and nucleus movement in the direction of membrane retraction. This mechanism allows Wnt signaling to control cell orientation, polarity and directional movement to positional cues from chemokine gradients and is parallel to the previously discussed non-canonical Wnt-RhoA pathway.

\section{Wht signaling and desmosomes}

Desmosomes are cell junctions primarily made of desmosomal cadherins, including desmocollins and desmogleins, plakoglobin ( $\gamma$-catenin) and members of the plakin family of cytolinkers. Desmosomes have been considered as not only a static structure but also a signaling center $[137,138]$. The connection of desmosomes and Wnt signaling is derived largely from the resemblance between plakoglobin and $\beta$-catenin. As the central molecules in desmosomes and adherent junctions, plakoglobin and $\beta$-catenin are interchangeable in these roles, and plakoglobin interacts with, and possibly competes for, many of the same binding partners as $\beta$-catenin. Fur- thermore, these two diverse proteins can function both in cell adhesion and in signaling in the nucleus [139]. Overexpression of plakoglobin induces axis duplication in Xenopus, suggesting the involvement of plakoglobin in $\mathrm{Wnt} / \beta$-catenin signaling [140]. Indeed, overexpression of either $\beta$-catenin or plakoglobin can activate a Wnt-responsive reporter and the Nr-CAM promoter containing TCF/LEF-binding site [141]. Plakoglobin could stimulate $\mathrm{Wnt} / \beta$-catenin signaling indirectly by affecting $\beta$ catenin localization and/or stability, since expression of cytoplasmic-restricted membrane-anchored plakoglobin still induces axis duplication [142]. However, the effects of plakoglobin can also be direct and negative, since plakoglobin binds to an adjacent site on Tcf- 4 along with $\beta$ catenin. The interaction between plakoglobin and Tcf-4 depends on the phosphorylation status of Tcf-4, and this interaction negatively affects the transcriptional activity of Tcf-4 [143]. Similar to $\beta$-catenin, phosphorylation of plakoglobin also affects its affinity to different interacting partners and is crucial for its subcellular localizations. Phosphorylation of tyrosine 549 of plakoglobin by the tyrosine kinase Fer increases the binding affinity of plakoglobin to $\alpha$-catenin of adherent junctions and upregulates the transcriptional activity of the $\beta$-cateninTcf-4 complex, possibly through the substitution for $\beta$-catenin in the adherent complex [144] (Figure 4B). In support of the idea that the influences of plakoglobin on Wnt/ $\beta$-catenin signaling depend on its subcellular localization, down-regulation of the desmosomal component desmoplakin results in nuclear localization of plakoglobin and a reduction of $\mathrm{Wnt} / \beta$-catenin signaling in cardiac myocytes [145]. Previous studies have shown loss of desmoglein-2 in gastric cancer [146, 147], desmocollin-2 in colorectal cancer [148] and desmocollin-3 in breast cancer [149], and it will be interesting to see whether or how these mutations may affect Wnt signaling in their respective contexts. In addition to affecting Wnt/ $\beta$-catenin signaling, nucleus-localized plakoglobin can also activate c-myc and Bcl-2 genes and promote cell proliferation (for a review, see [137]). Desmosomes seem to sequester plakoglobin, just like sequestering of $\beta$-catenin by adherent junctions, but further studies are needed to clarify how regulation of the balance between junctional and nuclear pools of these proteins may play a role in cancer and other cellular processes.

\section{Wnt signaling and cilia}

Growing evidence indicates connections between cilium/ciliogenesis and both $\beta$-catenin-dependent and -independent Wnt signal transduction. Inversin has been suggested as a switch between canonical and non-canon- 
ical Wnt signaling during renal development in response to fluid flow over the primary cilium [127]. It has been proposed that extracellular fluid flow increases Inversin expression and subsequently leads to cytoplasmic (but not membrane-associated) DVL degradation. In this model, the presence of fluid flow over the primary cilium changes the location of DVL from the cytosol to the membrane through Inversin expression and proteasomal degradation, which then switches a Wnt signal from $\beta$ catenin-dependent to $\beta$-catenin-independent signaling [127]. Another good example comes from the study of the zebrafish cystic kidney gene seahorse. The transcript of seahorse is highly enriched in heavily ciliated tissues and is closely associated with ciliary functions, such as establishment of left-right asymmetry. In consistence with its functions, seahorse genetically interacts with inversin, although it is dispensable for cilia assembly or motility. Interestingly, Seahorse associates with DVL, constrains the canonical Wnt pathway and promotes the non-canonical Wnt pathway during gastrulation. These results provide an additional link between ciliary signals and Wnt pathways [150].

In addition, the PCP protein VANGL2 localizes to the cilia of both renal and bronchial epithelial cells. It has been shown that VANGL2 interacts genetically with basal body-specific proteins whose dysfunction causes Bardet-Biedl syndrome (BBS), such as BBS1, BBS4 and BBS6 [151, 152]. Mice with mutated BBS genes display phenotypes that overlap with PCP mutants, such as open eye lids, incomplete neural tube closure and disrupted stereociliary bundles in the inner ear [151, 152]. Nonetheless, the temporal relationship between cilium/ ciliogenesis and Wnt signaling remains elusive. Defects in maintenance of primary cilium and the loss of normal signaling in cilium may disrupt the balance between canonical and non-canonical Wnt signaling, triggering dysregulated cell proliferation and differentiation, which ultimately contribute to cancer.

\section{Concluding remarks}

Wnt signaling appears to be involved in multiple aspects of tumorigenesis. Extensive studies have focused on the regulation of $\beta$-catenin levels by the destruction complex, but growing evidence suggests that links between Wnt signaling and the cytoskeleton are also involved in tumorigenesis. Clearly, the relationship between Wnt and well-known regulators of cancer cell motility, such as APC, Rho family GTPases, Diaphanousrelated formins, adherent and desmosomal junctions, and cilia-related proteins, provides ample areas for further investigation.

\section{Acknowledgments}

Like many Wnt reviews, we have attempted to summarize a field that is characterized by an enormous and rapidly growing body of literature, and we apologize if we have made any oversights or omissions, which are unintended. RTM is an Investigator of the Howard Hughes Medical Institute, AJC is the recipient of a Mentored Career Development Award from the National Institutes of Health/National Cancer Institute and SL is the recipient of a Speedy Horse Award from the National Science Council of Taiwan. We are indebted to these agencies for their continued support of our research efforts.

\section{References}

1 Davidson $\mathrm{G}, \mathrm{Wu} \mathrm{W}$, Shen J, et al. Casein kinase $1 \gamma$ couples Wnt receptor activation to cytoplasmic signal transduction. Nature 2005; 438:867-872.

2 Zeng X, Tamai K, Doble B, et al. A dual-kinase mechanism for Wnt co-receptor phosphorylation and activation. Nature 2005; 438:873-877.

3 Moon RT, Kohn AD, Ferrari GVD, Kaykas A. WNT and $\beta$-catenin signalling: diseases and therapies. Nat Rev Genet 2004; 5:691-701.

4 Tolwinski NS, Wieschaus E. Rethinking WNT signaling. Trends Genet 2004; 20:177-181.

5 Nelson WJ, Nusse R. Convergence of Wnt, $\beta$-catenin, and cadherin pathways. Science 2004; 303:1483-1487.

6 He X, Semenov M, Tamai K, Zeng X. LDL receptor-related proteins 5 and 6 in $\mathrm{Wnt} / \beta$-catenin signaling: arrows point the way. Development 2004; 131:1663-1677.

7 Torban E, Kor C, Gros P. Van Gogh-like2 (Strabismus) and its role in planar cell polarity and convergent extension in vertebrates. Trends Genet 2004; 20:570-577.

8 Veeman MT, Axelrod JD, Moon RT. A second canon: functions and mechanisms of $\beta$-catenin-independent Wnt signaling. Dev Cell 2003; 5:367-377.

9 Wallingford JB, Habas R. The developmental biology of Dishevelled: an enigmatic protein governing cell fate and cell polarity. Development 2005; 132:4421-4436.

10 Kim GH, Han JK. JNK and ROK $\alpha$ function in the noncanonical Wnt/RhoA signaling pathway to regulate Xenopus convergent extension movements. Dev Dyn 2005; 232:958968.

11 Darken RS, Scola AM, Rakeman AS, et al. The planar polarity gene strabismus regulates convergent extension movements in Xenopus. EMBO J 2002; 21:976-985.

12 Goto T, Keller R. The planar cell polarity gene strabismus regulates convergence and extension and neural fold closure in Xenopus. Dev Biol 2002; 247:165-181.

13 Park M, Moon RT. The planar cell-polarity gene stbm regulates cell behaviour and cell fate in vertebrate embryos. Nat Cell Biol 2002; 4:20-25.

14 Kibar Z, Vogan KJ, Groulx N, et al. Ltap, a mammalian homolog of Drosophila Strabismus/Van Gogh, is altered in the mouse neural tube mutant Loop-tail. Nat Genet 2001; 28:251-255.

15 Carreira-Barbosa F, Concha ML, Takeuchi M, et al. Prickle 1 regulates cell movements during gastrulation and neuronal 
migration in zebrafish. Development 2003; 130:4037-4046.

16 Takeuchi M, Nakabayashi J, Sakaguchi T, et al. The prickleRelated Gene in vertebrates is essential for gastrulation cell movements. Curr Biol 2003; 13:674-679.

17 Veeman MT, Slusarski DC, Kaykas A, Louie SH, Moon RT. Zebrafish Prickle, a modulator of noncanonical Wnt/Fz signaling, regulates gastrulation movements. Curr Biol 2003; 13:680-685.

18 Curtin JA, Quint E, Tsipouri V, et al. Mutation of Celsr1 disrupts planar polarity of inner ear hair cells and causes severe neural tube defects in the mouse. Curr Biol 2003; 13:11291133.

19 Qian D, Jones C, Rzadzinska A, et al. Wnt5a functions in planar cell polarity regulation in mice. Dev Biol 2007; 306:121133.

20 Kohn AD, Moon RT. Wnt and calcium signaling: $\beta$-cateninindependent pathways. Cell Calcium 2005; 38:439-446.

21 Slusarski DC, Pelegri F. Calcium signaling in vertebrate embryonic patterning and morphogenesis. Dev Biol 2007; 307:1-13.

22 Slusarski DC, Yang-Snyder J, Busa WB, Moon RT. Modulation of embryonic intracellular $\mathrm{Ca}^{2+}$ signaling byWnt-5A. Dev Biol 1997; 182:114-120.

23 Sheldahl LC, Park M, Malbon CC, Moon RT. Protein kinase $\mathrm{C}$ is differentially stimulated by Wnt and Frizzled homologs in a G-protein-dependent manner. Curr Biol 1999; 9:695-698.

24 Topczewski J, Sepich DS, Myers DC, et al. The zebrafish glypican knypek controls cell polarity during gastrulation movements of convergent extension. Dev Cell 2001; 1:251264.

25 Hikasa H, Shibata M, Hiratani I, Taira M. The Xenopus receptor tyrosine kinase Xror2 modulates morphogenetic movements of the axial mesoderm and neuroectoderm via Wnt signaling. Development 2002; 129:5227-5239.

26 Kuhl M, Sheldahl LC, Malbon CC, Moon RT. $\mathrm{Ca}^{2+} /$ calmodulin-dependent protein kinase II is stimulated by Wnt and Frizzled Homologs and promotes ventral cell fates in Xenopus. J Biol Chem 2000; 275:12701-12711.

27 Heisenberg CP, Tada M, Rauch GJ, et al. Silberblick/Wnt11 mediates convergent extension movements during zebrafish gastrulation. Nature 2000; 405:76-81.

28 Gilland E, Miller AL, Karplus E, Baker R, Webb SE. Imaging of multicellular large-scale rhythmic calcium waves during zebrafish gastrulation. Proc Natl Acad Sci USA 1999; 96:157161.

29 Wallingford JB, Ewald AJ, Harland RM, Fraser SE. Calcium signaling during convergent extension in Xenopus. Curr Biol 2001; 11:652-661

30 Westfall TA, Brimeyer R, Twedt J, et al. Wnt-5/pipetail functions in vertebrate axis formation as a negative regulator of Wnt/ $\beta$-catenin activity. J Cell Biol 2003; 162:889-898.

31 Kilian B, Mansukoski H, Barbosa FC, et al. The role of Ppt/ Wnt5 in regulating cell shape and movement during zebrafish gastrulation. Mech Dev 2003; 120:467-476.

32 Weeraratna AT, Jiang Y, Hostetter G, et al. Wnt5a signaling directly affects cell motility and invasion of metastatic melanoma. Cancer Cell 2002; 1:279-288.

33 Dejmek J, Safholm A, Kamp NC, Andersson T, Leandersson $\mathrm{K}$. Wnt-5a/Ca ${ }^{2+}$-induced NFAT activity is counteracted by Wnt-5a/Yes-Cdc42-casein kinase $1 \alpha$ signaling in human mammary epithelial cells. Mol Cell Biol 2006; 26:6024-6036.

34 Ma L, Wang HY. Suppression of cyclic GMP-dependent protein kinase is essential to the $\mathrm{Wnt} / \mathrm{cGMP} / \mathrm{Ca}^{2+}$ pathway. $J$ Biol Chem 2006; 281:30990-31001.

35 Krylova O, Messenger MJ, Salinas PC. Dishevelled-1 regulates microtubule stability: a new function mediated by glycogen synthase kinase-3ß. J Cell Biol 2000; 151:83-94.

36 Ciani L, Krylova O, Smalley MJ, Dale TC, Salinas PC. A divergent canonical WNT-signaling pathway regulates microtubule dynamics: dishevelled signals locally to stabilize microtubules. J Cell Biol 2004; 164:243-253.

37 Ciani L, Salinas P. c-Jun N-terminal kinase (JNK) cooperates with Gsk3 $\beta$ to regulate Dishevelled-mediated microtubule stability. BMC Cell Biol 2007; 8:27.

38 Chang L, Jones Y, Ellisman MH, Goldstein LS, Karin M. JNK1 is required for maintenance of neuronal microtubules and controls phosphorylation of microtubule-associated proteins. Dev Cell 2003; 4:521-533.

39 Schlessinger K, McManus EJ, Hall A. Cdc42 and noncanonical Wnt signal transduction pathways cooperate to promote cell polarity. J Cell Biol 2007; 178:355-361.

40 Zhang X, Zhu J, Yang GY, et al. Dishevelled promotes axon differentiation by regulating atypical protein kinase C. Nat Cell Biol 2007; 9:743-754.

41 Rosso SB, Sussman D, Wynshaw-Boris A, Salinas PC. Wnt signaling through Dishevelled, Rac and JNK regulates dendritic development. Nat Neurosci 2005; 8:34-42.

42 Fan S, Ramirez SH, Garcia TM, Dewhurst S. Dishevelled promotes neurite outgrowth in neuronal differentiating neuroblastoma $2 \mathrm{~A}$ cells, via a DIX-domain dependent pathway. Brain Res Mol Brain Res 2004; 132:38-50.

43 Capelluto DGS, Kutateladze TG, Habas R, et al. The DIX domain targets dishevelled to actin stress fibres and vesicular membranes. Nature 2002; 419:726-729.

44 Kinzler KW, Vogelstein B. Lessons from hereditary colorectal cancer. Cell 1996; 87:159-170.

45 Bienz M, Clevers H. Linking colorectal cancer to Wnt signaling. Cell 2000; 103:311-320.

46 Cadigan KM, Nusse R. Wnt signaling: a common theme in animal development. Genes Dev 1997; 11:3286-3305.

47 Fodde R, Smits R, Clevers H. APC, signal transduction and genetic instability in colorectal cancer. Nat Rev Cancer 2001; 1:55-67.

48 Polakis P. Wnt signaling and cancer. Genes Dev 2000; 14:1837-1851.

49 Samowitz WS, Powers MD, Spirio LN, et al. $\beta$-Catenin mutations are more frequent in small colorectal adenomas than in larger adenomas and invasive carcinomas. Cancer Res 1999; 59:1442-1444.

50 Mimori-Kiyosue Y, Shiina N, Tsukita S. Adenomatous polyposis coli (APC) protein moves along microtubules and concentrates at their growing ends in epithelial cells. J Cell Biol 2000; 148:505-518.

51 Munemitsu S, Souza B, Muller O, et al. The APC gene product associates with microtubules in vivo and promotes their assembly in vitro. Cancer Res 1994; 54:3676-3681.

$52 \mathrm{Su}$ LK, Burrell M, Hill DE, et al. APC binds to the novel protein EB1. Cancer Res 1995; 55:2972-2977. 
53 Askham JM, Moncur P, Markham AF, Morrison EE. Regulation and function of the interaction between the APC tumour suppressor protein and EB1. Oncogene 2000; 19:1950-1958.

54 Jimbo T, Kawasaki Y, Koyama R, et al. Identification of a link between the tumour suppressor APC and the kinesin superfamily. Nat Cell Biol 2002; 4:323-327.

55 Mimori-Kiyosue Y, Shiina N, Tsukita S. The dynamic behavior of the APC-binding protein EB1 on the distal ends of microtubules. Curr Biol 2000; 10:865-868.

56 Wen Y, Eng CH, Schmoranzer J, et al. EB1 and APC bind to $\mathrm{mDia}$ to stabilize microtubules downstream of Rho and promote cell migration. Nat Cell Biol 2004; 6:820-830.

57 Zumbrunn J, Kinoshita K, Hyman AA, Nathke IS. Binding of the adenomatous polyposis coli protein to microtubules increases microtubule stability and is regulated by GSK3 $\beta$ phosphorylation. Curr Biol 2001; 11:44-49.

58 Etienne-Manneville S, Hall A. Cdc42 regulates GSK-3 $\beta$ and adenomatous polyposis coli to control cell polarity. Nature 2003; 421:753-756.

59 Grohmann A, Tanneberger K, Alzner A, Schneikert J, Behrens J. AMER1 regulates the distribution of the tumor suppressor APC between microtubules and the plasma membrane. J Cell Sci 2007; 120:3738-3747.

60 Nathke IS, Adams CL, Polakis P, Sellin JH, Nelson WJ. The adenomatous polyposis coli tumor suppressor protein localizes to plasma membrane sites involved in active cell migration. J Cell Biol 1996; 134:165-179.

61 Salinas PC. Modulation of the microtubule cytoskeleton: a role for a divergent canonical Wnt pathway. Trends Cell Biol 2007; 17:333-342.

62 Schlesinger A, Shelton CA, Maloof JN, Meneghini M, Bowerman B. Wnt pathway components orient a mitotic spindle in the early Caenorhabditis elegans embryo without requiring gene transcription in the responding cell. Genes Dev 1999; 13:2028-2038.

63 Zhang H, Skop AR, White JG. Src and Wnt signaling regulate dynactin accumulation to the P2-EMS cell border in C. elegans embryos. J Cell Sci 2008; 121:155-161.

64 Lu B, Roegiers F, Jan LY, Jan YN. Adherens junctions inhibit asymmetric division in the Drosophila epithelium. Nature 2001; 409:522-525.

65 Purro SA, Ciani L, Hoyos-Flight M, et al. Wnt regulates axon behavior through changes in microtubule growth directionality: a new role for adenomatous polyposis coli. J Neurosci 2008; 28:8644-8654.

66 Watanabe T, Wang S, Noritake J, et al. Interaction with IQGAP1 links APC to Rac1, Cdc42, and actin filaments during cell polarization and migration. Dev Cell 2004; 7:871-883.

67 Briggs MW, Sacks DB. IQGAP1 as signal integrator: $\mathrm{Ca}^{2+}$, calmodulin, Cdc42 and the cytoskeleton. FEBS Lett 2003; 542:7-11.

68 Bashour AM, Fullerton AT, Hart MJ, Bloom GS. IQGAP1, a Rac- and Cdc42-binding protein, directly binds and crosslinks microfilaments. J Cell Biol 1997; 137:1555-1566.

69 Fukata M, Watanabe T, Noritake J, et al. Rac1 and Cdc42 capture microtubules through IQGAP1 and CLIP-170. Cell 2002; 109:873-885.

70 Kawasaki Y, Senda T, Ishidate T, et al. Asef, a link between the tumor suppressor APC and G-protein signaling. Science
2000; 289:1194-1197.

71 Akiyama T, Kawasaki Y. Wnt signalling and the actin cytoskeleton. Oncogene 2006; 25:7538-7544.

72 Kawasaki Y, Sato R, Akiyama T. Mutated APC and Asef are involved in the migration of colorectal tumour cells. Nat Cell Biol 2003; 5:211-215.

73 Nadauld LD, Chidester S, Shelton DN, et al. Dual roles for adenomatous polyposis coli in regulating retinoic acid biosynthesis and Wnt during ocular development. Proc Natl Acad Sci USA 2006; 103:13409-13414.

74 Eisinger AL, Nadauld LD, Shelton DN, et al. The adenomatous polyposis coli tumor suppressor gene regulates expression of cyclooxygenase- 2 by a mechanism that involves retinoic acid. J Biol Chem 2006; 281:20474-20482.

75 Tanegashima K, Zhao H, Dawid IB. WGEF activates Rho in the Wnt-PCP pathway and controls convergent extension in Xenopus gastrulation. EMBO J 2008; 27:606-617.

76 Kovar DR. Molecular details of formin-mediated actin assembly. Curr Opin Cell Biol 2006; 18:11-17.

77 Higgs HN. Formin proteins: a domain-based approach. Trends Biochem Sci 2005; 30:342-353.

78 Goode BL, Eck MJ. Mechanism and function of formins in control of actin assembly. Annu Rev Biochem 2007: 76:593627.

79 Watanabe N, Higashida C. Formins: processive cappers of growing actin filaments. Exp Cell Res 2004; 301:16-22.

80 Zigmond SH, Evangelista M, Boone C, et al. Formin leaky cap allows elongation in the presence of tight capping proteins. Curr Biol 2003; 13:1820-1823.

81 Evangelista M, Pruyne D, Amberg DC, Boone C, Bretscher A. Formins direct Arp2/3-independent actin filament assembly to polarize cell growth in yeast. Nat Cell Biol 2002; 4:32-41.

82 Wallar BJ, Alberts AS. The formins: active scaffolds that remodel the cytoskeleton. Trends Cell Biol 2003; 13:435-446.

83 Higgs HN, Peterson KJ. Phylogenetic analysis of the formin homology 2 domain. Mol Biol Cell 2005; 16:1-13.

84 Alberts AS. Identification of a carboxyl-terminal diaphanousrelated formin homology protein autoregulatory domain. $J$ Biol Chem 2001; 276:2824-2830.

85 Lammers M, Rose R, Scrima A, Wittinghofer A. The regulation of mDial by autoinhibition and its release by Rho*GTP. EMBO J 2005; 24:4176-4187.

86 Habas R, Kato Y, He X. Wnt/Frizzled activation of Rho regulates vertebrate gastrulation and requires a novel Formin homology protein Daam1. Cell 2001; 107:843-854.

87 Liu W, Sato A, Khadka D, et al. Mechanism of activation of the Formin protein Daam1. Proc Natl Acad Sci USA 2008; 105:210-215.

88 Marlow F, Topczewski J, Sepich D, Solnica-Krezel L. Zebrafish Rho kinase 2 acts downstream of Wnt11 to mediate cell polarity and effective convergence and extension movements. Curr Biol 2002; 12:876-884.

89 Habas R, He X. In: William E, Balch C (eds). Activation of Rho and Rac by Wnt/Frizzled Signaling. New York: Academic Press, 2006:500-511.

90 Sato A, Khadka DK, Liu W, et al. Profilin is an effector for Daam1 in non-canonical Wnt signaling and is required for vertebrate gastrulation. Development 2006; 133:4219-4231.

91 Lu J, Meng W, Poy F, et al. Structure of the FH2 domain of 
Daam1: implications for formin regulation of actin assembly. J Mol Biol 2007; 369: 1258-1269.

92 Aspenstrom P, Richnau N, Johansson AS. The diaphanousrelated formin DAAM1 collaborates with the Rho GTPases RhoA and Cdc42, CIP4 and Src in regulating cell morphogenesis and actin dynamics. Exp Cell Res 2006; 312:21802194.

93 Kida YS, Sato T, Miyasaka KY, Suto A, Ogura T. Daam1 regulates the endocytosis of EphB during the convergent extension of the zebrafish notochord. Proc Natl Acad Sci USA 2007; 104:6708-6713.

94 Lawrenson ID, Wimmer-Kleikamp SH, Lock P, et al. EphrinA5 induces rounding, blebbing and de-adhesion of EphA3expressing $293 \mathrm{~T}$ and melanoma cells by CrkII and Rhomediated signalling. J Cell Sci 2002; 115 (Part 5):1059-1072.

95 Batlle E, Henderson JT, Beghtel H, et al. $\beta$-catenin and TCF mediate cell positioning in the intestinal epithelium by controlling the expression of EphB/ephrinB. Cell 2002; 111:251263.

96 Guo DL, Zhang J, Yuen ST, et al. Reduced expression of EphB2 that parallels invasion and metastasis in colorectal tumours. Carcinogenesis 2006; 27:454-464.

97 Clevers H, Batlle E. EphB/EphrinB receptors and Wnt signaling in colorectal cancer. Cancer Res 2006; 66:2-5.

98 Zhu S, Liu L, Korzh V, Gong Z, Low BC. RhoA acts downstream of Wnt5 and Wnt11 to regulate convergence and extension movements by involving effectors Rho Kinase and Diaphanous: use of zebrafish as an in vivo model for GTPase signaling. Cell Signal 2006; 18:359-372.

99 Lai SL, Chang CN, Wang PJ, Lee SJ. Rho mediates cytokinesis and epiboly via ROCK in zebrafish. Mol Reprod Dev 2005; 71:186-196.

100 Carreira S, Goodall J, Denat L, et al. Mitf regulation of Dia1 controls melanoma proliferation and invasiveness. Genes Dev 2006; 20:3426-3439.

101 Preudhomme C, Roumier C, Hildebrand MP, et al. Nonrandom 4 p13 rearrangements of the RhoH/TTF gene, encoding a GTP-binding protein, in non-Hodgkin's lymphoma and multiple myeloma. Oncogene 2000; 19:2023-2032.

102 Reuther GW, Lambert QT, Booden MA, et al. Leukemia-associated Rho guanine nucleotide exchange factor, a Dbl family protein found mutated in leukemia, causes transformation by activation of RhoA. J Biol Chem 2001; 276:27145-27151.

103 Kourlas PJ, Strout MP, Becknell B, et al. Identification of a gene at 11q23 encoding a guanine nucleotide exchange factor: evidence for its fusion with MLL in acute myeloid leukemia. Proc Natl Acad Sci USA 2000; 97:2145-2150.

104 Clark EA, Golub TR, Lander ES, Hynes RO. Genomic analysis of metastasis reveals an essential role for RhoC. Nature 2000; 406:532-535.

105 Aznar S, Fernandez-Valeron P, Espina C, Lacal JC. Rho GTPases: potential candidates for anticancer therapy. Cancer Lett 2004; 206:181-191.

106 Gomez del PT, Benitah SA, Valeron PF, Espina C, Lacal JC. Rho GTPase expression in tumourigenesis: evidence for a significant link. Bioessays 2005; 27:602-613.

107 Jauliac S, Lopez-Rodriguez C, Shaw LM, et al. The role of NFAT transcription factors in integrin-mediated carcinoma invasion. Nat Cell Biol 2002; 4:540-544.
108 Yoeli-Lerner M, Yiu GK, Rabinovitz I, et al. Akt blocks breast cancer cell motility and invasion through the transcription factor NFAT. Mol Cell 2005; 20:539-550.

109 Cottrell S, Bicknell D, Kaklamanis L, Bodmer WF. Molecular analysis of APC mutations in familial adenomatous polyposis and sporadic colon carcinomas. Lancet 1992; 340:626630.

110 Powell SM, Zilz N, Beazer-Barclay Y, et al. APC mutations occur early during colorectal tumorigenesis. Nature 1992; 359:235-237.

111 Morin PJ, Sparks AB, Korinek V, et al. Activation of $\beta$ catenin-Tcf signaling in colon cancer by mutations in $\beta$ catenin or APC. Science 1997; 275:1787-1790.

112 Liu C, Kato Y, Zhang Z, et al. $\beta$-Trcp couples $\beta$-catenin phosphorylation-degradation and regulates Xenopus axis formation. Proc Natl Acad Sci USA 1999; 96:6273-6278.

113 Liu C, Li Y, Semenov M, et al. Control of $\beta$-catenin phosphorylation/degradation by a dual-kinase mechanism. Cell 2002; 108:837-847.

114 Amit S, Hatzubai A, Birman Y, et al. Axin-mediated CKI phosphorylation of $\beta$-catenin at Ser 45: a molecular switch for the Wnt pathway. Genes Dev 2002; 16:1066-1076.

115 Brembeck FH, Rosario M, Birchmeier W. Balancing cell adhesion and Wnt signaling, the key role of $\beta$-catenin. Curr Opin Genet Dev 2006; 16:51-59.

116 Roura S, Miravet S, Piedra J, de Herreros AG, Dunach M. Regulation of E-cadherin/catenin association by tyrosine phosphorylation. J Biol Chem 1999; 274:36734-36740.

117 Piedra J, Miravet S, Castano J, et al. p120 Catenin-associated Fer and Fyn tyrosine kinases regulate $\beta$-catenin Tyr-142 phosphorylation and $\beta$-catenin- $\alpha$-catenin interaction. Mol Cell Biol 2003; 23:2287-2297.

118 Aberle H, Schwartz H, Hoschuetzky H, Kemler R. Single amino acid substitutions in proteins of the armadillo gene family abolish their binding to $\alpha$-catenin. J Biol Chem 1996; 271:1520-1526.

119 Pokutta S, Weis WI. Structure of the Dimerization and $\beta$-Catenin- Binding Region of $\alpha$-Catenin. Molecular Cell 2000/3; 5:533-543.

120 Piedra J, Martinez D, Castano J, et al. Regulation of $\beta$ Catenin Structure and Activity by Tyrosine Phosphorylation. Journal of Biological Chemistry 2001/6/1; 276:20436-20443.

121 Castano J, Raurell I, Piedra JA, et al. $\beta$-Catenin N- and Cterminal tails modulate the coordinated binding of adherens junction proteins to $\beta$-catenin. J Biol Chem 2002; 277:3154131550.

122 Brembeck FH, Schwarz-Romond T, Bakkers J, et al. Essential role of BCL9-2 in the switch between $\beta$-catenin's adhesive and transcriptional functions. Genes Dev 2004; 18:22252230.

123 Graveel C, Su Y, Koeman J, et al. Activating Met mutations produce unique tumor profiles in mice with selective duplication of the mutant allele. Proc Natl Acad Sci USA 2004; 101:17198-17203.

124 Wang Z, Shen D, Parsons DW, et al. Mutational Analysis of the Tyrosine Phosphatome in Colorectal Cancers. Science 2004; 304:1164-1166.

$125 \mathrm{Li} \mathrm{S}$. Src kinase signaling in leukaemia. Int J Biochem Cell Biol 2007; 39:1483-1488. 
126 Hilbig A. Src kinase and pancreatic cancer. Recent Results Cancer Res 2008; 177:179-185.

127 Simons M, Gloy J, Ganner A, et al. Inversin, the gene product mutated in nephronophthisis type II, functions as a molecular switch between Wnt signaling pathways. Nat Genet 2005; 37:537-543.

128 Orsulic S, Huber O, Aberle H, Arnold S, Kemler R. Ecadherin binding prevents $\beta$-catenin nuclear localization and $\beta$-catenin/LEF-1-mediated transactivation. J Cell Sci 1999; 112 (Part 8): 1237-1245.

129 Graham TA, Weaver C, Mao F, Kimelman D, Xu W. Crystal structure of a $\beta$-catenin/Tcf complex. Cell 2000; 103:885896.

130 von Kries JP, Winbeck G, Asbrand C, et al. Hot spots in $\beta$ catenin for interactions with LEF-1, conductin and APC. Nat Struct Biol 2000; 7:800-807.

131 Huber AH, Weis WI. The structure of the $\beta$-catenin/E-cadherin complex and the molecular basis of diverse ligand recognition by $\beta$-catenin. Cell 2001; 105:391-402.

132 Stockinger A, Eger A, Wolf J, Beug H, Foisner R. E-cadherin regulates cell growth by modulating proliferation-dependent $\beta$-catenin transcriptional activity. J Cell Biol 2001; 154:11851196.

133 Gottardi CJ, Wong E, Gumbiner BM. E-cadherin suppresses cellular transformation by inhibiting $\beta$-catenin signaling in an adhesion-independent manner. J Cell Biol 2001; 153:10491060 .

134 Stigliano I, Puricelli L, Filmus J, et al. Glypican-3 regulates migration, adhesion and actin cytoskeleton organization in mammary tumor cells through Wnt signaling modulation. Breast Cancer Res Treat 2009;114:251-262.

135 Witze ES, Litman ES, Argast GM, Moon RT, Ahn NG. Wnt5a control of cell polarity and directional movement by polarized redistribution of adhesion receptors. Science 2008; 320:365-369.

136 Satyamoorthy K, Muyrers J, Meier F, Patel D, Herlyn M. Mel-CAM-specific genetic suppressor elements inhibit melanoma growth and invasion through loss of gap junctional communication. Oncogene 2001; 20:4676-4684.

137 Chidgey M, Dawson C. Desmosomes: a role in cancer? $\mathrm{Br} J$ Cancer 2007; 96:1783-1787.

138 Green KJ, Simpson CL. Desmosomes: new perspectives on a classic. J Invest Dermatol 2007; 127:2499-2515.

139 Getsios S, Huen AC, Green KJ. Working out the strength and flexibility of desmosomes. Nat Rev Mol Cell Biol 2004; 5:271-281.
140 Karnovsky A, Klymkowsky MW. Anterior axis duplication in Xenopus induced by the over-expression of the cadherinbinding protein Plakoglobin. Proc Natl Acad Sci USA 1995; 92:4522-4526.

141 Conacci-Sorrell ME, Ben-Yedidia T, Shtutman M, et al. NrCAM is a target gene of the $\beta$-catenin/LEF-1 pathway in melanoma and colon cancer and its expression enhances motility and confers tumorigenesis. Genes Dev 2002; 16:20582072.

142 Merriam JM, Rubenstein AB, Klymkowsky MW. Cytoplasmically anchored plakoglobin induces a WNT-like phenotype in Xenopus. Dev Biol 1997; 185:67-81.

143 Miravet S, Piedra J, Miro F, et al. The transcriptional factor Tcf-4 contains different binding sites for $\beta$-catenin and plakoglobin. J Biol Chem 2002; 277:1884-1891.

144 Miravet S, Piedra J, Castano J, et al. Tyrosine phosphorylation of plakoglobin causes contrary effects on its association with desmosomes and adherens junction components and modulates $\beta$-catenin-mediated transcription. Mol Cell Biol 2003; 23:7391-7402.

145 Garcia-Gras E, Lombardi R, Giocondo MJ, et al. Suppression of canonical Wnt/ $\beta$-catenin signaling by nuclear plakoglobin recapitulates phenotype of arrhythmogenic right ventricular cardiomyopathy. J Clin Invest 2006; 116:2012-2021.

146 Biedermann K, Vogelsang H, Becker I, et al. Desmoglein 2 is expressed abnormally rather than mutated in familial and sporadic gastric cancer. J Pathol 2005; 207:199-206.

147 Yashiro M, Nishioka N, Hirakawa K. Decreased expression of the adhesion molecule desmoglein-2 is associated with diffuse-type gastric carcinoma. Eur J Cancer 2006; 42:23972403.

148 Khan K, Hardy R, Haq A, et al. Desmocollin switching in colorectal cancer. Br J Cancer 2006; 95:1367-1370.

149 Oshiro M, Kim C, Wozniak R, et al. Epigenetic silencing of DSC3 is a common event in human breast cancer. Breast Cancer Res 2005; 7:R669-R680.

150 Kishimoto N, Cao Y, Park A, Sun Z. Cystic kidney gene seahorse regulates cilia-mediated processes and Wnt pathways. Dev Cell 2008; 14:954-961.

151 Ross AJ, May-Simera H, Eichers ER, et al. Disruption of Bardet-Biedl syndrome ciliary proteins perturbs planar cell polarity in vertebrates. Nat Genet 2005; 37:1135-1140.

152 Blacque OE, Leroux MR. Bardet-Biedl syndrome: an emerging pathomechanism of intracellular transport. Cell Mol Life Sci 2006; 63:2145-2161. 